\title{
Bronchogenic carcinoma presenting as an injured thumb
}

\author{
A. B. CROSS \\ Accident and Emergency Department, East Birmingham Hospital, Birmingham, England
}

\section{SUMMARY}

A case of bronchogenic carcinoma presenting as a hand injury is described. The difficulties in diagnosis are highlighted. The importance of radiology is demonstrated. Palliative surgery is recommended for pain relief.

\section{INTRODUCTION}

Metastatic lesions developing in the phalanges of the hand are well recognized, with the origin of the tumour usually known. Where malignant disease is not suspected, such lesions escape diagnosis, particularly when the patient presents with an injury.

\section{CASE REPORT}

A 74-year-old, retired regimental sergeant major attended the accident and emergency department with a history of having trapped his right thumb in an ambulance door 4 weeks previously. According to the patient there had been no abnormality of the digit before the injury. Two weeks after his accident he attended his family doctor as the thumb was still painful, swollen and bruised. The nail was trephined but the digit continued to swell and became more painful, so he was sent to hospital (Fig. 1). A diagnosis of infected haematoma was made and the pulp of the thumb was incised. No pus was obtained and there was little haemorrhage. As the pain continued despite antibiotics and analgesics, the patient returned after 3 days. An X-ray of the thumb (Fig. 2) showed gross absorption of the terminal phalanx, suggestive of a neoplasm. A chest X-ray film revealed a large hilar mass consistent with a bronchial neoplasm (Fig. 3).

Correspondence: $\mathrm{Mr}$ A. B. Cross, Accident and Emergency Department, East Birmingham Hospital, Bordesley Green East, Birmingham, B9 5ST, England 


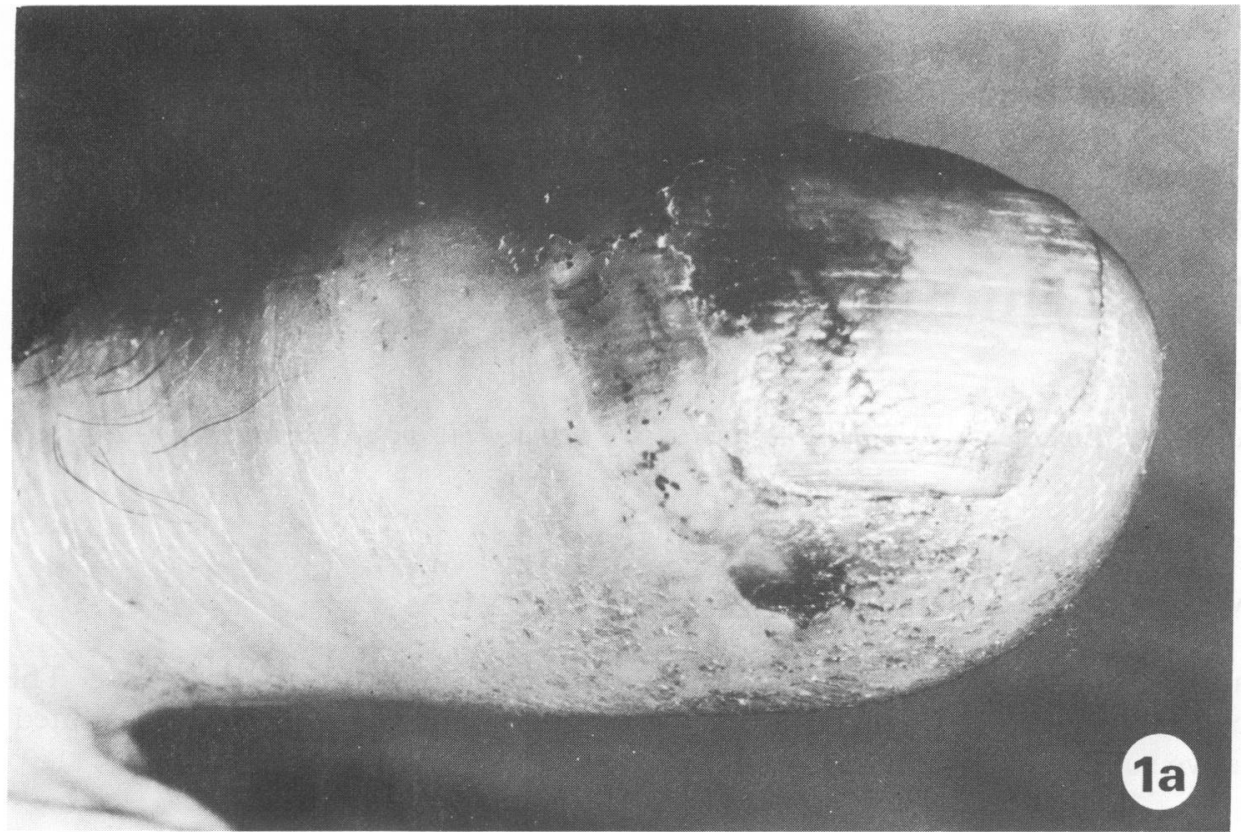

$\mathbb{8}$

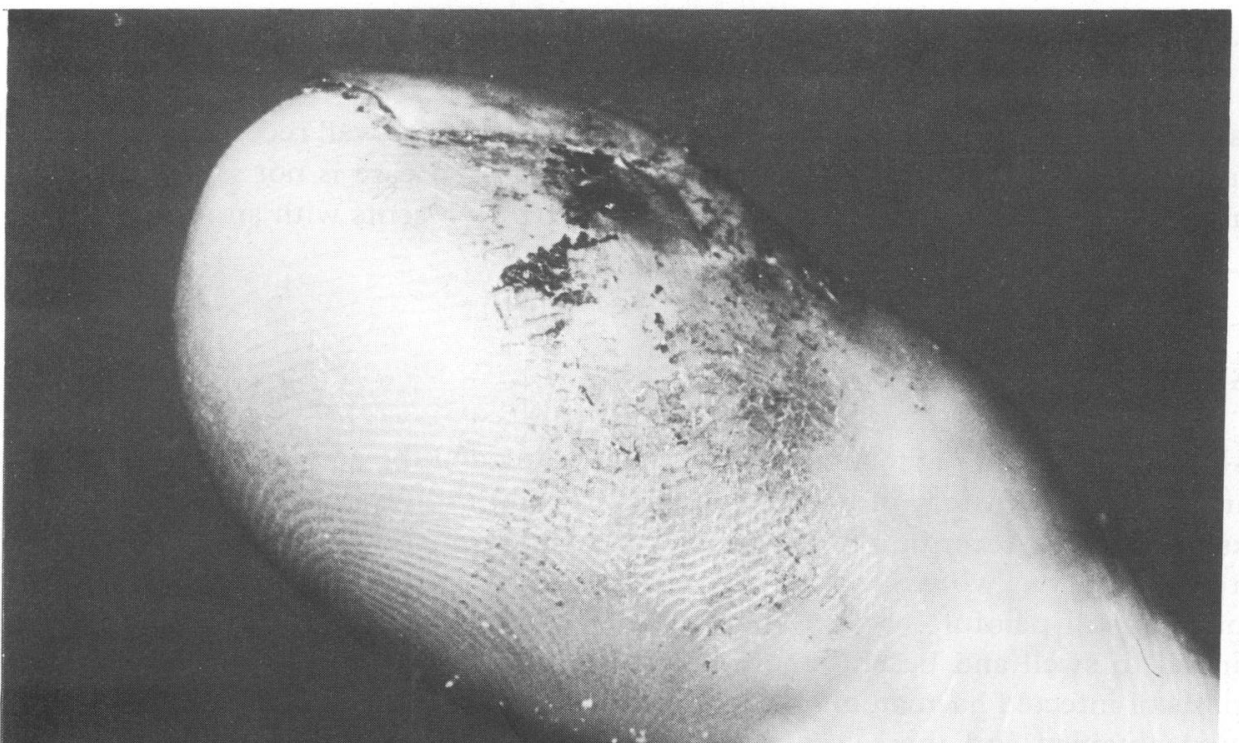

Fig. 1 Swollen right thumb showing a subungual haematoma. 


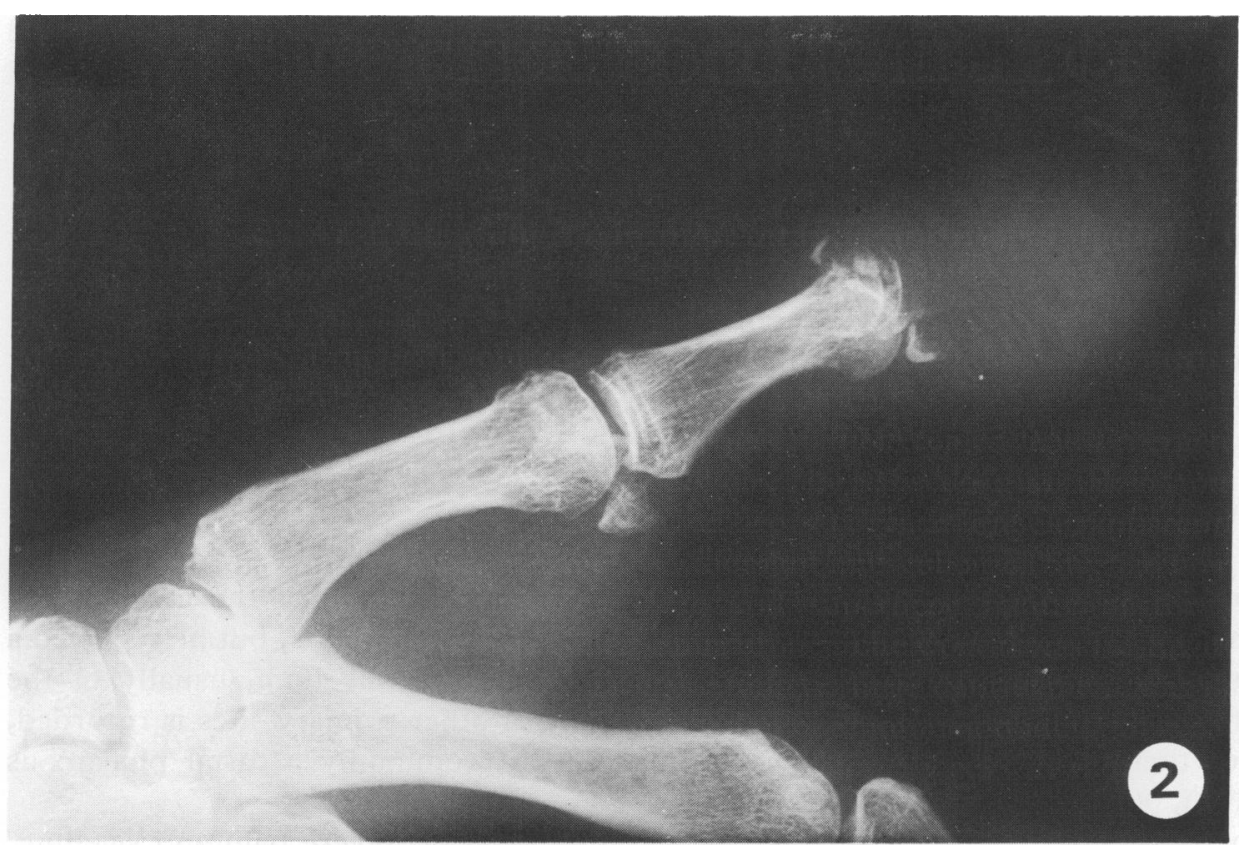

Fig. $2 \mathrm{X}$-ray of the right thumb with extensive bone absorption of the terminal phalanx.

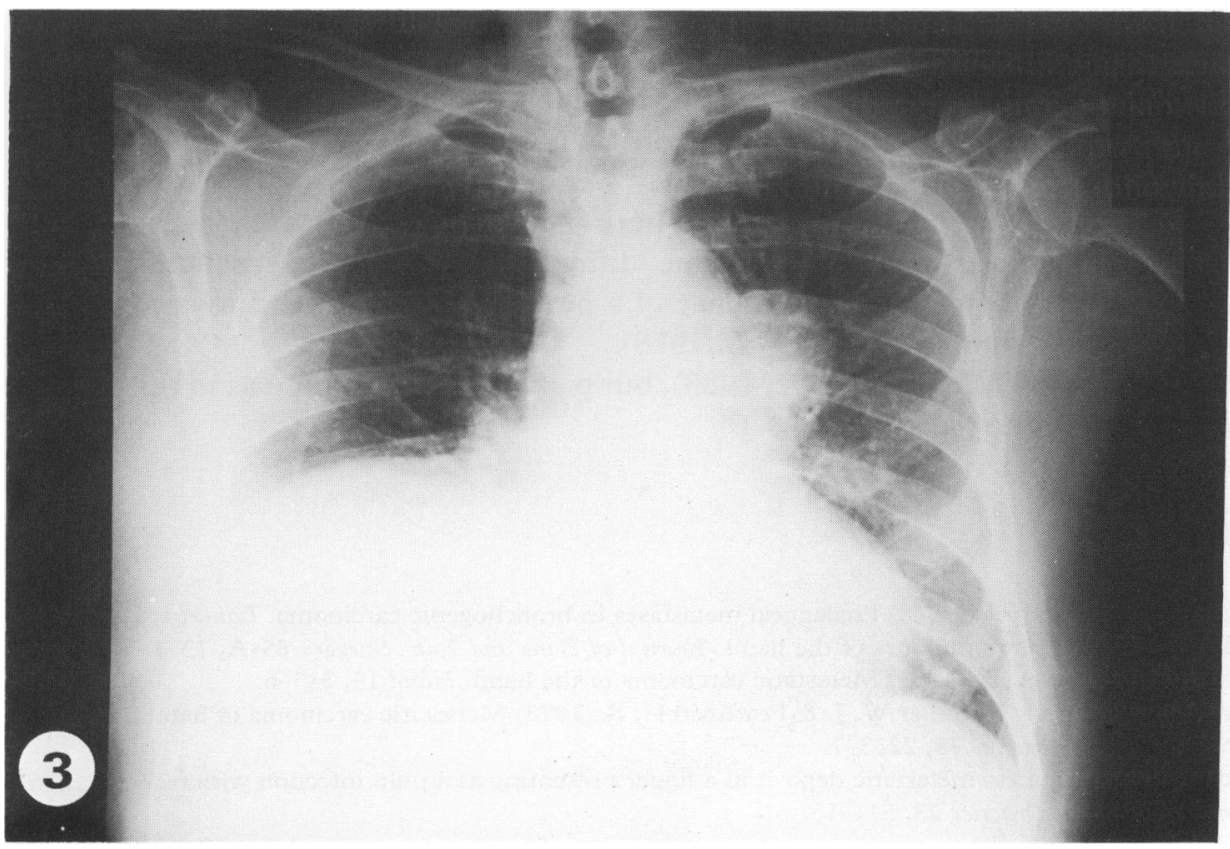

Fig. 3 Chest X-ray showing a large left hilar mass, the source of the neoplasm. 
This man had had a stroke 9 years before, leaving a residual mild left-sidedm hemiplegia. Four years later, following an attack of bronchitis, a chest X-ray showed paralysis of the right diaphragm, but no lung disease was found. He smoked a pipe but not cigarettes.

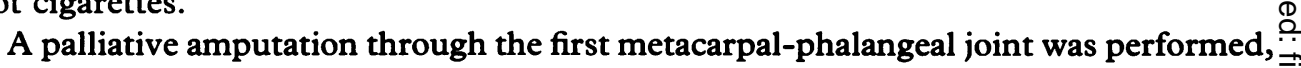
resulting in total pain relief. The stump healed rapidly leaving a usefully functioning hand.

Histology showed a poorly differentiated squamous cell carcinoma consistent with a $\frac{\bar{C}}{\bar{c}}$ bronchial origin. The patient remained in moderate, pain-free health for 3 months but $\frac{\widetilde{\Phi}}{\widetilde{\pi}}$ his condition then rapidly deteriorated and he died 4 months after his first attendance.

\section{DISCUSSION}

Kerin (1983), in his extensive review of the literature, found that the incidence of secondary tumour in the hand was little over $0.1 \%$ of all metastases, but he reported aî series of over 150 cases. Half the tumours originated in the lung, usually of the ${ }_{0}^{N}$ squamous cell type (Strang, 1952). A wide variety of other primary sites is recorded, and of these breast and kidney predominate. Most commonly a distal phalanx is involved, often of the thumb.

The presenting features are either, or a combination of, severe pain and swelling. Injury has been noted on several occasions but was never the reason for consultation. In $\vec{\oplus}$ this case medical advice was sought to relieve the severe pain attributed to the injury, the release of a subungual haematoma only intensifying the pain. Secondary infectioni was then thought to be responsible for the patient's severe pain. According to Snedd (1969), infective lesions such as pulp-space infection and osteomyelitis are a commoñ diagnosis in these cases, often resulting in an inappropriate operation (Colson \&ڤ్ Willcox, 1948).

Radiography was the key to the diagnosis here and must be undertaken in swellings of $\overline{\vec{\partial}}$ a digit when diagnosis is in doubt. The differentiation between malignancy and infection may be difficult, but the absence of a periosteal reaction and invasion of theo joint space suggest tumour (Patel et al., 1978).

Prognosis is poor (Martin \& Dove, 1983), but palliative amputation, as in this case, is $\frac{3}{3}$. justified to relieve the pain.

\section{REFERENCES}

Colson G. M. \& Willcox A. (1948) Phalangeal metastases in bronchogenic carcinoma. Lancet i, $100-2$.

Kerin R. (1983) Metastatic tumours of the hand. Fournal of Bone and Foint Surgery 65-A, 1331-5.

Martin K. A. \& Dove A. F. (1983) Metastatic carcinoma of the hand. Hand 15, 343-6.

Patel M. R., Sanchez H. J., Silver W. J. \& Pearlman H. S. (1978) Metastatic carcinoma of hand. New York State Fournal of Medicine 78, 2233-7.

Sneddon J. (1969) Painless metastatic deposit in a finger presenting as a pulp infection with osteitis. British
fournal of Clinical Practice 23, 511-13.

Strang R. (1952) Phalangeal metastases as a first clinical sign of bronchogenic carcinoma. British fournal of: Surgery 39, 372-3. 